\title{
Modulating toll-like receptor-mediated inflammatory responses following exposure of whole cell and lipopolysaccharide component from Porphyromonas gingivalis in Wistar rat models
}

\author{
Sindy Cornelia Nelwan ${ }^{1}$, Ricardo Adrian Nugraha ${ }^{2}$, Anang Endaryanto ${ }^{3}$, Indrawati Retno ${ }^{4}$
}

Correspondence: Dr. Sindy Cornelia Nelwan

Email: sindyjayakusuma@yahoo.com

\begin{abstract}
'Department of Pediatric Dentistry, Faculty of Dentistry, Universitas Airlangga, Surabaya, Indonesia, 2Department of Medicine, Faculty of Medicine, Universitas Airlangga, Surabaya, Indonesia, ${ }^{3}$ Department of Child Health, Faculty of Medicine, Universitas Airlangga, Surabaya, Indonesia, ${ }^{4}$ Department of Oral Biology, Faculty of Dentistry, Universitas Airlangga, Surabaya, Indonesia
\end{abstract}

\section{ABSTRACT}

Objective: To explore host innate inflammatory response and the signal pathway induced by Porphyromonas gingivalis by measuring level of toll-like receptor 2 (TLR2) and TLR4 activity. Materials and Methods: Animal experimental study with pretest-posttest controlled group design were done between January 1 and December 10, 2016. . Total of 28 wistar rats had been used, randomized into 7 groups, each were given various dose of intra-sulcural injection of Porphyromonas gingivalis lipopolysaccharide. Statistical Analysis: Normality were measured by Shapiro-Wilk test, while statistical analysis made by ANOVA, $t$ test, Pearson, and linear regression model.. Results: At day 0, no significant difference TLR2 and TLR4 level were measured. At day 4, there is a slight difference between TLR2 and TLR4 level in each group. At day 11, there is a significant difference between TLR2 and TLR4 level in each group. Group with exposure of whole cell will develop greater TLR2 but lower TLR4 level. In the contrary, group with exposure of LPS will develop greater TLR4 but lower TLR2 level. Conclusion: Our data supported that $P$. gingivalis played a vital role in the pathogenesis of pathogen-induced inflammatory responses in which TLR2 and TLR4 have different molecular mechanisms following recognition of pathogens and inflammatory response.

Key words: Innate immunity, lipopolysaccharide, Porphyromonas gingivalis, toll-like receptor, whole cell

\section{INTRODUCTION}

In this decade, toll-like receptors (TLRs) had been well established as key parts of natural immunity involved in the early phase of host immunity against pathogens. ${ }^{[1]}$ Belong to a wide family of proteins which act as an activator of innate immunity signaling



pathway, TLRs play their role by activating several receptors for the proinflammatory cytokines, such as interleukin-1. ${ }^{[2]}$

This is an open access article distributed under the terms of the Creative Commons Attribution-NonCommercial-ShareAlike 3.0 License, which allows others to remix, tweak, and build upon the work non-commercially, as long as the author is credited and the new creations are licensed under the identical terms.

For reprints contact: reprints@medknow.com

How to cite this article: Nelwan SC, Nugraha RA, Endaryanto A, Retno I. Modulating toll-like receptor-mediated inflammatory responses following exposure of whole cell and lipopolysaccharide component from Porphyromonas gingivalis in Wistar rat models. Eur $\mathrm{J}$ Dent 2017;11:422-6.

DOI: 10.4103/ejd.ejd_147_17 
Since animals and humans react differently to the pathogens, these variations allow pathogens to escape from immunity. We learned several differences of host immune responses, as measured by TLR2 and TLR4 following infection of Gram-negative facultative anaerobic bacteria such as Porphyromonas gingivalis. As long as researchers study about genomic projects, only small portion of the genetic variability observed in the innate immune response is accounted in these pathways. ${ }^{[3]}$

TLR2 and TLR4 are responsible in recruiting polymorphonuclear neutrophils and macrophage in the early phase of inflammation, which directly and indirectly stimulate proinflammatory cytokine. Both TLR2 and TLR4 play dominant role in the equilibrium of pathogen infection and host inflammatory response system during the early phase of inflammation. Thus, it may be important to learn deeper about activity of TLR2 and TLR4 after some pathogens infection. ${ }^{[4]}$

One huge kinds of pathogen who had unique property that altered host innate immunity differently is $P$. gingivalis. This bacterium was commonly found in the oral cavity, contributes to the appearance of periodontal disease and gingivitis in children, as well as it may be found and play a small role in the upper gastrointestinal infections, upper respiratory tract infection, and colon infections. It has also been isolated from women with bacterial vaginosis although the mechanisms and host responses following that infections are not fully understood..$^{[5]}$

Following exposure of periodontal pathogens $P$. gingivalis, we can observe early host-agent interaction in the supporting microenvironment and proper recognition by host defense system, for example, TLRs expressed on multiple monocyte populations, including dendritic cells, macrophages, and T-cells. ${ }^{[6-8]}$

Different innate immunity response system following $P$. gingivalis infection may induce different signaling pathway, and different signals transduced by TLRs also likely shape the subsequent acquired inflammatory responses that regulate $\mathrm{T}$-cell and cytokine-induced macrophage activation; thus, proper TLR signaling is considered very important and well positioned to keep the suitable hosts' outcome following exposure of $P$. gingivalis. ${ }^{[9,10]}$

By some ways to adapt as parasitic pathogens, $P$. gingivalis had many ways to evade host immune responses by significantly change their lipopolysaccharide (LPS) and cell wall in order not only to affects its virulence but also to escape from host immune responses.

Therefore, in this paper, we investigated the different host innate immunity response as measured by TLR2 and TLR4 level, following exposure of whole cell and bacterial LPS of $P$. gingivalis.

\section{MATERIALS AND METHODS}

\section{Materials}

1. LPS of $P$. gingivalis (Astarte Biologics, WA, USA, in intrasulcular injection of low dose $0.3 \mu \mathrm{g} / \mathrm{ml}$, medium dose $1 \mu \mathrm{g} / \mathrm{ml}$, and high dose $3 \mu \mathrm{g} / \mathrm{ml}$ )

1. Whole cell (Pg) of $P$. gingivalis (Astarte Biologics, WA, USA, in intrasulcular injection of low-dose $9 \times 10^{7} \mathrm{CFU}$, medium-dose $9 \times 10^{9} \mathrm{CFU}$, and high-dose $9 \times 10^{11} \mathrm{CFU}$ )

2. TLR2 and TLR4 were measured in plasma by direct sandwich ELISA (R\&D System Europe Ltd., Abingdon, UK) according to manufacturer's instructions. All measurements were done in duplicates and values averaged for analysis.

\section{Ethics statement}

Ethical approval to carry out this study was granted by Airlangga Oral and Dental Hospital in collaboration with College of Dentistry Research Ethics Committee (DREC Ref: 72/13) and Universitas Airlangga College of Medicine Research Council (Ref: MREC/A/1768).

\section{Animals}

Twenty-eight male Wistar rats (age 8-10 weeks, weight 120-150 g) were randomized and divided into seven groups of intervention:

- Group A: Placebo intrasulcular

- Group B1: $0.3 \mu \mathrm{g} / \mathrm{ml}$ LPS P. gingivalis intrasulcular injected

- Group B2: $1 \mu \mathrm{g} / \mathrm{ml}$ LPS P. gingivalis intrasulcular injected

- Group B3: $3 \mu \mathrm{g} / \mathrm{ml}$ LPS P. gingivalis intrasulcular injected

- Group C1:9 $10^{7} \mathrm{CFU}$ of $P$. gingivalis intrasulcular injected

- Group C2: $9 \times 10^{9} \mathrm{CFU}$ of $P$. gingivalis intrasulcular injected

- Group C3:9 × 1011 CFU of $P$. gingivalis intrasulcular injected.

\section{Experimental procedures}

Samples were conducted with euthanasia protocols. The entire sample was taken blood serum at day 
0 (before intrasulcular injection), day 4 (after intrasulcular injection), and day 11 (after intrasulcular injection) and seen the activity of TLR2 and TLR4 with direct sandwich enzyme-linked immunosorbent assay.

\section{Study design}

Pretest-posttest controlled group design was done in this study. We extracted 28 Wistar rats and randomized them into seven groups. There were no significant age and body weight differences. Within each group, we measured serum sample of TLR2 and TLR4 before experiments began (day 0 ).

After 4 days and 11 days, serum samples were also taken in both groups. The activity of TLR2 and TLR4 were measured by direct sandwich ELISA.

\section{Statistical analysis}

Data analysis has been performed using SPSS version 17.0 (IBM Corp., Chicago, IL, USA). The assumption of normality distribution data has been tested by Shapiro-Wilk (SW) normality test. SW test showed $W=0.892516, V=3.416357, P=0.055$, means that the data are normally distributed.

Statistical analyses were done using Student's $t$-test and analysis of variant (ANOVA). Results were presented as means \pm standard errors. The paired $t$-test and ANOVA were used to test differences between level of TLR2 and TLR4 in each period among single groups of Wistar rats. On the other hand, independent $t$-test and ANOVA were used to test differences between level of TLR2 and TLR4 in the different groups in the same period.

Pearson's Chi-square test was used to test for correlations between laboratory markers. Univariate (crude values) and multiple linear regression (adjusted coefficient) analyses were used to test for association or to identify variables which predict different levels of laboratory markers. The level of significance between groups was set at $P<0.05$.

\section{RESULTS}

Results of the study include a comparison table between groups: A (control group/placebo); B1 (treated by low-dose Pg LPS injection, $0.3 \mu \mathrm{g} / \mathrm{ml}$ ); B2 (treated by medium-dose Pg LPS injection, $1 \mu \mathrm{g} / \mathrm{ml}$ ); B3 (treated by high dose of LPS injection, $3 \mu \mathrm{g} / \mathrm{ml}$ ); $\mathrm{C} 1$ (treated by low dose of whole cell injection $9 \times 10^{7} \mathrm{CFU}$ ); C2 (treated by medium dose of whole cell injection
$9 \times 10^{9} \mathrm{CFU}$ ); and C3 (treated by high dose of whole cell injection $\left.9 \times 10^{11} \mathrm{CFU}\right)$.

Plot profile of ELISA examination on each group with TLR2 and TLR4 measurement.

1. TLR2 and TLR4 level before experiments began (day 0)

Table 1 shows the relationship between TLR2 and TLR4 on day 0 .

There is no difference significantly in TLR2 and TLR4 at day 0 before injection, this can be concluded that all participants were randomized to ensure the internal validity.

2. TLR2 and TLR4 level 4 days after exposure (day 4)

Table 2 shows the relationship between TLR2 and TLR4 on day 4 .

There is a slight difference in TLR2 and TLR4 level after 4 days of exposure; this can be seen at the level TLR2 and TLR4 in each group. TLR2 level is greatest at placebo group (A) and lowest at low dose (C1) and high dose of whole cell group (C3). On the other hand, TLR4 level is the greatest at high-dose LPS group (B1) and lowest at low dose of whole cell group (C1).

3. TLR2 and TLR4 level 11 days after exposure (day 11)

\begin{tabular}{|c|c|c|c|}
\hline \multirow[t]{2}{*}{ Group } & \multirow[t]{2}{*}{$n$} & \multicolumn{2}{|c|}{ Level (pg/ml) } \\
\hline & & TLR2 & TLR4 \\
\hline $\bar{A}$ & 4 & $1.99 \pm 0.75$ & $1.78 \pm 0.87$ \\
\hline B1 & 4 & $2.16 \pm 0.32$ & $2.10 \pm 0.71$ \\
\hline B2 & 4 & $1.98 \pm 0.53$ & $1.53 \pm 0.95$ \\
\hline B3 & 4 & $2.98 \pm 0.89$ & $1.14 \pm 0.75$ \\
\hline C1 & 4 & $0.83 \pm 0.63$ & $1.56 \pm 0.83$ \\
\hline $\mathrm{C} 2$ & 4 & $0.55 \pm 0.55$ & $1.50 \pm 0.73$ \\
\hline C3 & 4 & $0.58 \pm 0.97$ & $1.78 \pm 0.63$ \\
\hline$p$ & & 0.053 & 0.137 \\
\hline
\end{tabular}

\begin{tabular}{lccc}
$\begin{array}{l}\text { Table 2: Toll-like receptor } 2 \text { and toll-like receptor } \\
\text { 4 day } 4\end{array}$ & \multicolumn{2}{c}{ Level (pg/ml) } \\
\hline Group & $\boldsymbol{n}$ & TLR2 & TLR4 \\
\cline { 2 - 4 } & & $3.53 \pm 0.93$ & $2.18 \pm 1.62$ \\
\hline A & 4 & $3.79 \pm 0.23$ & $2.99 \pm 0.75$ \\
B1 & 4 & $2.75 \pm 0.75$ & $3.33 \pm 1.02$ \\
B2 & 4 & $2.52 \pm 0.75$ & $3.77 \pm 1.05$ \\
B3 & 4 & $0.61 \pm 0.85$ & $0.99 \pm 0.55$ \\
C1 & 4 & $0.97 \pm 0.75$ & $1.25 \pm 0.35$ \\
C2 & 4 & $0.71 \pm 0.57$ & $1.59 \pm 0.37$ \\
C3 & 4 & 0.035 & 0.041 \\
$p$ & & &
\end{tabular}


Table 3 shows the relationship between TLR2 and TLR4 on day 11.

There is a slight difference in TLR2 and TLR4 level after 4 days of exposure; this can be seen at the level TLR2 and TLR4 in each group. TLR2 level is greatest at placebo group (A) and lowest at low dose (C1) and high dose of whole cell group (C3). On the other hand, TLR4 level is the greatest at high-dose LPS group (B1) and lowest at low dose of whole cell group (C1).

\section{DISCUSSION}

The activation of macrophages and monocytes by periodontal pathogen is mediated by pathogens-associated molecular pattern and pattern recognition receptors including the TLR. In particular, LPS is released as a consequence from the damage of $P$. gingivalis cell wall, and it can maximize the activation of innate immunity signaling pathway. ${ }^{[11]}$

Several literatures suggest that host reacts differently to the different parts of $P$. gingivalis body part. Host recognition of LPS requires a specific receptor, which belongs to the TLR4. Bacterial LPS acts dominantly through TLR4 whereas whole cell components including peptidoglycan and lipoprotein responses are mediated dominantly by TLR2. ${ }^{[12]}$

It is well-known that TLR4 signaling upregulates and TLR2 signaling downregulates macrophage antibacterial activity. ${ }^{[11]}$ In our experiments using Wistar rats, following exposure of whole cell $P$. gingivalis, level of TLR2 increases significantly and level of TLR4 decreases significantly. It may indicate bacterial property (other than LPS) which can turn off host innate immunity and host inflammatory response. Thus, their bacterial property can disrupt early recognition of $P$. gingivalis. ${ }^{[13]}$

\begin{tabular}{|c|c|c|c|}
\hline \multirow[t]{2}{*}{ Group } & \multirow[t]{2}{*}{$n$} & \multicolumn{2}{|c|}{ Level (pg/ml) } \\
\hline & & TLR2 & TLR4 \\
\hline $\bar{A}$ & 4 & $0.96 \pm 0.25$ & $2.69 \pm 0.55$ \\
\hline B1 & 4 & $0.54 \pm 0.35$ & $2.61 \pm 1.05$ \\
\hline B2 & 4 & $1.12 \pm 0.75$ & $2.12 \pm 1.25$ \\
\hline B3 & 4 & $0.69 \pm 0.33$ & $2.15 \pm 0.65$ \\
\hline $\mathrm{C} 1$ & 4 & $0.71 \pm 0.57$ & $0.98 \pm 0.17$ \\
\hline $\mathrm{C} 2$ & 4 & $0.75 \pm 0.59$ & $0.65 \pm 0.39$ \\
\hline $\mathrm{C} 3$ & 4 & $1.01 \pm 0.53$ & $0.54 \pm 0.25$ \\
\hline$p$ & & 0.247 & 0.025 \\
\hline
\end{tabular}

This unique property is not owned by another bacteria. Since bacterial LPS may stimulate a greater inflammatory response, compared to whole cell pathogens, we summarized that some part of these bacteria plays a major role in evading host immune responses particularly to the natural immunity. ${ }^{[14]}$ Therefore, different innate immunity responses could be found after exposure of different parts of these bacteria, and it may alter host response following periodontal pathogens infection. ${ }^{[15]}$ Downregulation of TLR4 and upregulation of TLR2 are anticipated by these pathogens for evading the exaggerated immune response. ${ }^{[16]}$

While these properties may be beneficial for pathogens, they are not always bad for the host. In previous experimental study, following these periodontal pathogen exposure, the absence of TLR2 had been accompanied by increased mortality, although the precise mechanisms of TLR2 involvement in host defense have not been identified. ${ }^{[17-19]}$ Activation of proinflammatory cytokine, release of huge numbers of leukocyte migration, and direct antimicrobial action of innate immunity induced by TLRs may play a major role of massive dilatation of blood vessel, ${ }^{[20]}$ increased level of reactive oxygen species, ${ }^{[21]}$ and end with damage to host cells. ${ }^{[22]}$

\section{CONCLUSION}

Porphyromonas gingivalis, bactery found in the oral cavity, played a vital role in pathogenesis of pathogeninduced inflammatory responses in which TLR2 and TLR4 have different molecular mechanisms following recognition of pathogens and inflammatory response.

Exposure to lipopolysaccharide of Porphyromonas gingivalis had been shown to stimulate level of TLR2 and depress level of TLR4 in wistar rats, whereas exposure to whole cell had been shown to stimulate level of TLR4 and depress level of TLR2.

Different molecular pattern following exposure of various component of bacteria may be interesting to be studied further. As different molecular pattern may induce different activation pathway of proinflammatory cytokine, it can explain the involvement of TLR-independent recognition systems in the early response to Porphyromonas gingivalis infection by several individual reports.

\section{Limitations and strengths}

This study had limitations with regard to the animal trials and its limited number of samples that associate 
with the assessed TLR level as well as reported experience of human monocyte pathway in animals. These factors may have an impact on the interpretation of our results. Thus, our findings should be interpreted within the context of this study and its limitations. The strengths of the study were its high statistical power and the homogeneity of each group to enable comparison with the unexposed participants.

\section{Acknowledgments}

The authors would like to thank Prof. Dr. Soetojo as Dean of Faculty of Medicine and Dr. Darmawan Setijanto as Dean of Faculty of Dentistry Universitas Airlangga. The authors also thank all staffs and students from Universitas Airlangga, Departments of Pediatric Dentistry-Airlangga Oral and Dental Hospital, and Department of Pediatric-Airlangga School of Medicine - Dr. Soetomo General Hospital for their technical and academic contribution.

\section{Financial support and sponsorship}

Nil.

\section{Conflicts of interest}

There are no conflicts of interest.

\section{REFERENCES}

1. Owens BM, Moore JW, Kaye PM. IRF7 regulates TLR2-mediated activation of splenic CD11c(hi) dendritic cells. PLoS One 2012;7:e41050.

2. Brint EK, Fitzgerald KA, Smith P, Coyle AJ, Gutierrez-Ramos JC, Fallon PG, et al. Characterization of signaling pathways activated by the interleukin 1 (IL-1) receptor homologue T1/ST2. A role for Jun N-terminal kinase in IL-4 induction. J Biol Chem 2002;277:49205-11.

3. Alper S, Warg LA, De Arras L, Flatley BR, Davidson EJ, Adams J, et al. Novel innate immune genes regulating the macrophage response to gram positive bacteria. Genetics 2016;204:327-36.

4. Chen Q, Davidson TS, Huter EN, Shevach EM. Engagement of TLR2 does not reverse the suppressor function of mouse regulatory $\mathrm{T}$ cells, but promotes their survival. J Immunol 2009;183:4458-66.

5. Naito M, Hirakawa H, Yamashita A, Ohara N, Shoji M, Yukitake H, et al. Determination of the genome sequence of Porphyromonas gingivalis strain ATCC 33277 and genomic comparison with strain W83 revealed extensive genome rearrangements in P. gingivalis. DNA Res 2008;15:215-25.
6. Yanagawa $\mathrm{Y}$, Onoé K. Enhanced IL-10 production by TLR4-and TLR2-primed dendritic cells upon TLR restimulation. J Immunol 2007;178:6173-80.

7. Singh RK, Srivastava A, Singh N. Toll-like receptor signaling: A perspective to develop vaccine against leishmaniasis. Microbiol Res 2012;167:445-51.

8. Faria MS, Reis FC, Lima AP. Toll-like receptors in leishmania infections: Guardians or promoters? J Parasitol Res 2012;2012:930257.

9. Foey AD, Habil N, Al-Shaghdali K, Crean S. Porphyromonas gingivalis-stimulated macrophage subsets exhibit differential induction and responsiveness to interleukin-10. Arch Oral Biol 2017;73:282-8.

10. Wiyarni P, Imelda F, Retno I, Utomo H, Anang E, Harsono A. Changes in bacterial profiles after periodontal treatment associated with respiratory quality of asthmatic children. Paediatr Indones 2008; $48: 327-37$

11. Stasi A, Intini A, Divella C, Franzin R, Montemurno E, Grandaliano G, et al. Emerging role of lipopolysaccharide binding protein in sepsis-induced acute kidney injury. Nephrol Dial Transplant 2017:32:24-31.

12. Murray HW, Zhang Y, Zhang Y, Raman VS, Reed SG, Ma X. Regulatory actions of Toll-like receptor 2 (TLR2) and TLR4 in Leishmania donovani infection in the liver. Infect Immun 2013;81:2318-26.

13. Saraiva $\mathrm{M}, \mathrm{O}^{\prime}$ Garra A. The regulation of IL-10 production by immune cells. Nat Rev Immunol 2010;10:170-81.

14. Boke F, Gazioglu C, Akkaya S, Akkaya M. Relationship between orthodontic treatment and gingival health: A retrospective study. Eur J Dent 2014;8:373-80.

15. Zhu XQ, Lu W, Chen Y, Cheng KF, Qiu JY, Xu Y, et al. Effects of Porphyromonas gingivalis lipopolysaccharidetolerized monocytes on inflammatory responses in neutrophils. PLoS One 2016;11:e0161482.

16. Park S, Shin HJ, Shah M, Cho HY, Anwar MA, Achek A, et al. TLR4/MD2 specific peptides stalled in vivo LPS-induced immune exacerbation. Biomaterials 2017;126:49-60.

17. Takeuchi O, Hoshino K, Akira S. Cutting edge: TLR2-deficient and MyD88-deficient mice are highly susceptible to Staphylococcus aureus infection. J Immunol 2000;165:5392-6.

18. Koedel U, Angele B, Rupprecht T, Wagner H, Roggenkamp A, Pfister HW, et al. Toll-like receptor 2 participates in mediation of immune response in experimental pneumococcal meningitis. J Immunol 2003;170:438-44.

19. Echchannaoui H, Frei K, Schnell C, Leib SL, Zimmerli W, Landmann R. Toll-like receptor 2-deficient mice are highly susceptible to Streptococcus pneumoniae meningitis because of reduced bacterial clearing and enhanced inflammation. J Infect Dis 2002;186:798-806.

20. Kamak G, Yildrim E, Rencber E. Evaluation of the relationship between periodontal risk and carotid artery calcifications on panoramic radiographs. Eur J Dent 2015;9:483-9.

21. Gupta N, Gupta ND, Gupta A, Goyal L, Garg S. The influence of type 2 diabetes mellitus on salivary matrix metalloproteinase-8 levels and periodontal parameters: A study in an Indian population. Eur J Dent 2015;9:319-23.

22. Qureshi S, Medzhitov R. Toll-like receptors and their role in experimental models of microbial infection. Genes Immun 2003;4:87-94 